\title{
Physiology of suppression in strabismic amblyopia
}

\author{
Richard Harrad, Frank Sengpiel, Colin Blakemore
}

It is 100 years since von Graefe first demonstrated a suppression scotoma in an amblyopic eye. ${ }^{1}$ A review of publications on the subject of suppression in strabismus reveals that this has not been a very active area of research and that what literature there is contains many apparent contradictions.

Early workers found strong suppression at the fovea of the deviating eye in strabismic amblyopia (the point of confusion) and also at the diplopic point (the point on the retina of the deviating eye where the image of the target being fixated by the other eye falls). ${ }^{23}$ They made no attempt to describe the fate of images of objects in the rest of the visual field of the deviating eye. Subsequent experimental results have been conflicting: Pratt-Johnson and Tillson found the entire visual field of the deviating eye except the temporal crescent was suppressed in all strabismic subjects except those with monofixation syndrome ${ }^{4}$; Jampolsky reported hemiretinal suppression, ${ }^{5}$ and Sireteanu and Fronius described discrete areas of suppression surrounded by regions of facilitation and stereopsis in patients with monofixation syndrome. ${ }^{6}$ The area of suppression in the amblyopic eye depends on the nature of the stimuli used in the experiment ${ }^{24} 7$; patches of grating, different coloured lights, ${ }^{6}$ and geometrical patterns ${ }^{5}$ have all been used by various authors. There has been a tendency by some authors to generalise from data collected from a few patients with a particular type of amblyopia in an attempt to describe the condition in all patients. It is clear from detailed study of individual patients that no one simple explanation of suppression in amblyopia is sufficient and that a combination of physiological processes is at play.

\section{Psychophysical evidence}

Binocular rivalry occurs in normal humans when corresponding points in the two eyes view images that are so dissimilar that they cannot be fused. The observer experiences alternating dominance and suppression of each monocular image. ${ }^{89}$ The process that underlies binocular rivalry has been proposed as the physiological basis of suppression in amblyopia. ${ }^{310-12}$ However, there are a number of objections to this proposition: the characteristic alternation of binocular rivalry is not seen in strabismic suppression; the wavelength dependence of suppression in binocular rivalry differs from that of strabismic suppression ${ }^{13}$; suppression in strabismus has been found to be much stronger than rivalry suppression in normal subjects ${ }^{1415}$ and the visual stimuli that lead to binocular rivalry, such as gratings of different orientation in the two eyes, when presented to amblyopes tend to produce rivalry with alternation rather than suppression. 516

Dichoptic masking ${ }^{17} 18$ is the physiological process whereby a stimulus of a given contrast presented to one eye can prevent the detection of a lower contrast but otherwise identical stimulus presented to the other eye. This binocular inhibitory process has been found to be present in some amblyopic subjects ${ }^{19}$ and the work of Harrad and Hess has shown that, in the presence of reduced contrast sensitivity in the amblyopic eye, it can at least partly account for suppression in some subjects with small angle strabismus or anisometropic amblyopia, ${ }^{715}$ as well as for reduced stereoacuity in these patients. ${ }^{20}$

The loss of low contrast information as a result of dichoptic masking is similar to the process whereby a progressive reduction of the contrast of one of a pair of stereo half images leads to a decrease in stereoacuity ${ }^{21} 22$ and eventually suppression of the lower contrast half image in normal subjects. ${ }^{23}$ Observers with normal stereopsis suppress some of the monocular information contained in each stereo half image, a phenomenon called fusional suppression. ${ }^{24}$ McKee and Harrad $^{25}$ found that stereoanomalous subjects were able to extract monocular information from stereoscopic targets with the dominant eye, while this information was not available to the nondominant eye. They proposed that suppression in these subjects might simply be the effect of fusional suppression in the presence of a weakened binocular signal from the non-dominant or amblyopic eye.

Jampolsky ${ }^{5}$ and Schor ${ }^{16}$ found that similar targets tended to be the most effective stimuli for strabismic suppression (whereas binocular rivalry suppression in normal observers is produced only by dissimilar images in the two eyes). Since crossed or uncrossed disparities may be selectively affected in some stereoblind subjects, ${ }^{26} 27$ Schor speculated that stimulation of one class of disparity detector (crossed or uncrossed) might lead to suppression. ${ }^{28} \mathrm{He}$ found that in a group of subjects with small angle strabismus suppression was stimulated by the presentation of targets of a fixed disparity and that this disparity dependent suppression was present throughout the central visual field and was not confined to a particular retinal locus.

In a binocular rivalry paradigm clear differences in the depth of suppression between the different types of amblyopia have been reported ${ }^{14}$ : in anisometropic amblyopia suppression was weaker than in strabismic amblyopia and in alternate fixators it was strongest of all. Harrad and Hess found similar results and proposed that suppression was strongest where there was little or no capacity for binocular facilitation in the presence of large monocular pools of cells ${ }^{15}$; a similar hypothesis has been put forward by Blake. ${ }^{9}$ It seems that there is a combination of processes operating to bring about suppression; dichoptic masking or disparity dependent suppression are seen in anisometropia and small angle strabismus and, since normal physiological processes are utilised, suppression need not be very powerful. Where normal binocular interactions are not possible, in moderate and large angle strabismus, there seems to be a powerful form of binocular rivalry suppression.

Where in the visual system is rivalry suppression taking place? Lehky and Blake ${ }^{29}$ have suggested the lateral 
geniculate nucleus (LGN) or layer 4 of the primary visual cortex (V1) as likely sites, since most neurons in both of these loci are excitable through only one eye. Moreover, they are themselves selective for the orientation of line stimuli (layer 4 of the cortex, at least in the cat) or receive feedback input from orientation selective cells (for the LGN): such selectivity seems to be required to explain the orientation dependence of binocular rivalry.

On the basis of his own psychophysical findings, $\mathrm{Hess}^{30}$ reached a similar conclusion concerning the site of suppression in amblyopia. He investigated the perceptual adaptation caused by prolonged exposure to high contrast gratings ${ }^{31}$; because of its orientation dependence this phenomenon is thought to arise from neural effects within the visual cortex. He found that strabismic amblyopic subjects do not exhibit orientation dependent threshold elevation through the amblyopic eye after adaptation with both eyes open, but such an adaptation effect is seen when a grating is viewed by the amblyopic eye alone. He concluded that suppression takes place at (or before) the site of adaptation, probably in V1.

Since binocular rivalry may be implicated in strabismic suppression we undertook a neurophysiological investigation, looking for evidence of inhibitory binocular interactions in the LGN and V1 that might provide the neural basis of binocular rivalry suppression.

\section{Neurophysiology}

Varela and Singer ${ }^{32}$ had already reported that, when stimulated with a grating in their dominant eye, the responses of some cells in the LGN of the anaesthetised cats were suppressed if a grating of orthogonal orientation was presented to the other 'silent' eye, but were unaffected by a grating of the same orientation. However, neither we ${ }^{33}$ nor others ${ }^{34}$ have been able to confirm these findings.

Although several workers have carried out single cell recordings from cat primary visual cortex during the presentation of non-fusible stimuli, ${ }^{35-37}$ they did not find powerful interocular suppressive effects. But recently we have found conditions under which the majority of cortical neurons (outside layer 4) exhibit strong interocular inhibitory interactions which might account for binocular rivalry. ${ }^{33} 38$ We studied the responses of 52 neurons in V1 of five normal adult cats to dichoptic grating stimuli and found that, while binocular facilitation was observed with gratings of similar orientation, the response to a grating of optimal orientation presented to one eye was suppressed, for more than half of the 45 binocular cells ( 25 cells, $56 \%$ ), by a grating of very different orientation shown to the other eye (Fig 1). Facilitation with iso-oriented gratings amounted to $120.7 \% \pm 10.4 \%$ (mean \pm SEM) of monocular, dominant eye responses, while orthogonally oriented gratings reduced monocular responses by $37 \cdot 7 \% \pm 3 \cdot 8 \%$ (mean \pm SEM). In most cells, these effects are evident only if the suppressive stimulus is introduced while the cell is already responding through its dominant eye, not when the onset of stimulation in the two eyes is simultaneous. ${ }^{38}$ This correlates with the finding that simultaneously presented conflicting stimuli are temporarily fused by humans before the onset of rivalry. ${ }^{11}$ This temporal non-linearity explains why other workers, who used stimuli of simultaneous onset, did not see distinct suppressive interactions.

A recent preliminary report ${ }^{39}$ suggests that in awake monkeys a proportion of neurons in V1 similarly show suppression of neuronal activity that is correlated with perceptual suppression of vision in one eye during episodes of binocular rivalry.

Neurophysiological research into strabismic amblyopia
A

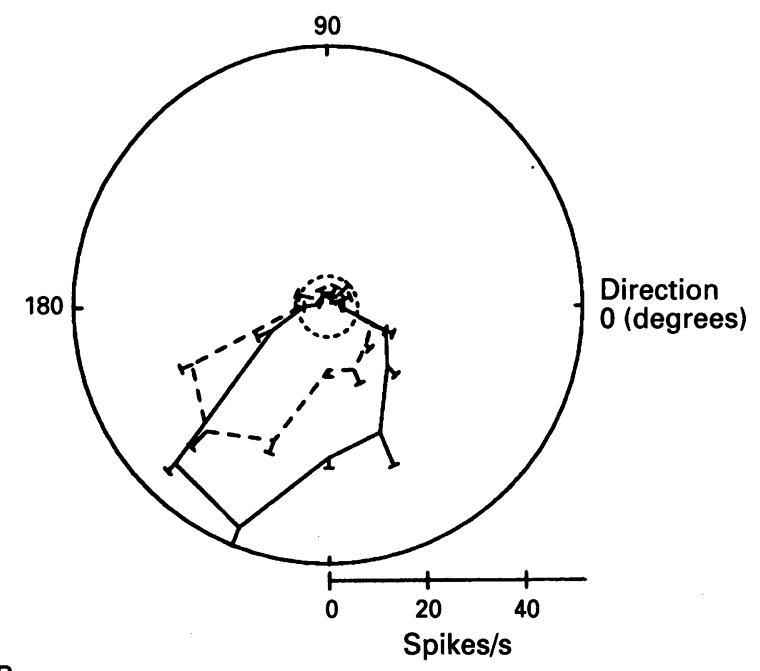

B

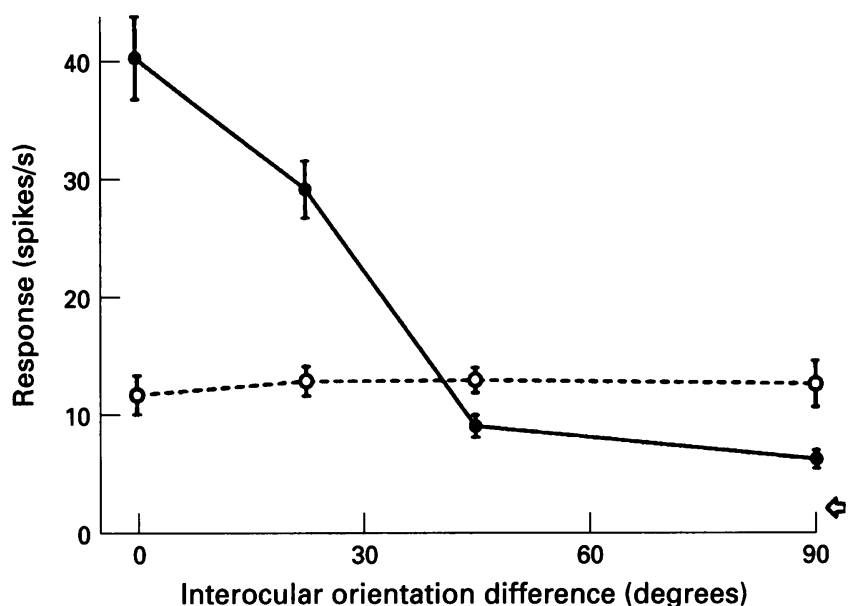

Figure 1 Orientation dependence of binocular interaction in a layer 6 complex cell recorded from a normal cat. (A) Polar plots of

orientation/direction tuning, showing mean responses (+1SEM) during monocular stimulation through the dominant eye (solid lines) and the non-dominant eye (broken line) alone, as a function of the direction of drift of sinusoidally modulated gratings (spatial frequency $=0.56 \mathrm{cpd}$

[cycles per degree]; drift frequency $=4 \mathrm{c} / \mathrm{s}$; contrast $=0.8$ ). The dotted circle in the centre indicates mean spontaneous activity. (B) Results of binocular interaction protocol. The dominant (contralateral) eye was continuously stimulated with a 'conditioning' grating of optimal orientation (direction of drift $=247.5^{\circ}$; spatial frequency $=0.56 \mathrm{cpd}$; temporal frequency $=4 \mathrm{c} / \mathrm{s}$; contrast $=0.4$ ) while gratings of the same spatial and temporal frequency (contrast $=0.8$ ) appeared intermittently in the ipsilateral eye at five different orientations, over a $90^{\circ}$ range, clockwise from that of the 'conditioning' stimulus. The abscissa indicates the difference in orientation between the stimuli shown to the two eyes. ( $\bullet$ Plots the mean response ( \pm 1 SEM) during binocular stimulation with a particular combination of gratings, while (O) plotted at the same position on the abscissa shows activity averaged over the immediately preceding periods of monocular stimulation. The open arrow indicates the mean level of spontaneous discharge. For this cell, binocular interaction changed from $285 \%$ facilitation above monocular response for iso-oriented gratings to $60 \%$ inhibition for orthogonal gratings.

until recently concentrated on a search for monocular response anomalies of cells at various stages in the primary visual pathway that might account for the severe acuity deficits that are often observed in strabismic humans as well as in animals with surgically induced squint. However, unless surgical intervention was so comprehensive as to severely compromise ocular motility, function and, perhaps, even the blood supply of the operated eye, ${ }^{4041}$ no differences were found between normal and strabismic animals in the properties of neurons in the visual pathway peripheral to the cortex. ${ }^{42}$

For cells in the primary visual cortex of strabismic cats $^{43-48}$ and monkeys, ${ }^{49-51}$ the most striking and also the only generally accepted consequence of squint is the 
breakdown of conventional binocularity - that is, most neurons can only be driven through the left or the right eye, seldom through both. In esotropic monkeys, a prevalence of cells dominated by the non-deviated eye has been reported, ${ }^{50}$ though most studies of strabismic monkeys and cats have reported equal proportions of cells dominated by each eye. ${ }^{43-4851} \mathrm{~A}$ range of further anomalies has been described, none of which is without controversy or severe enough to account for the phenomenon of strabismic amblyopia. 5253 In animals that have been deprived of vision in one eye, even for a very short time early in life, cells that are excitable through the previously deprived eye have a lower 'neural acuity' (the highest spatial frequency that evokes a detectable response) than do cells driven through the normal eye. ${ }^{54}$ This reduction in neural acuity clearly correlates with reduced behavioural acuity in an amblyopic eye and it might therefore be expected that cells in the visual cortex of esotropic animals would be similarly affected. In fact, Crewther and Crewther ${ }^{47}$ found only a small difference in the average acuity of cells through the two eyes, while the cells with the highest resolution through the squinting eye (which might be expected to determine behavioural acuity) were hardly different from those driven through the normal eye. Indeed, most authors have reported no difference at all in the spatial performance of neurons dominated by the fixing and the deviating eye in squinting cats and monkeys. ${ }^{55-57}$ However, it must be said that amblyopia verified by behavioural tests occurs in only a minority of esotropic (and probably even fewer exotropic) cats. ${ }^{57}$ But in most neurophysiological studies of the effects of strabismus, visual acuity has not been behaviourally tested and therefore it is not known whether the animals actually had amblyopia or not.

Only very few studies have investigated interocular suppression and its part in binocular integration as a possible basis for strabismic amblyopia. We addressed the possibility that mechanisms underlying normal binocular rivalry might be the basis of suppression in strabismic amblyopia. ${ }^{4858}$ Exotropia or esotropia were induced in five kittens by tenotomy of the medial or lateral rectus, respectively, just after eye opening. We recorded responses from 85 neurons in V1 of the adult cats, to pairs of drifting gratings covering 10 degrees of visual angle that were presented to corresponding positions in the visual fields of the two eyes (for further details of stimulation procedures, see captions to Figs 1 and 2). Receptive fields of all cells studied in these animals were within 4 degrees of the area centralis. Only seven cells (9\%) showed facilitatory binocular interactions close to normal. For 47 cells ( $55 \%$ of the total), presentation of a grating of any orientation caused significant suppression of the response being elicited through the cell's dominant eye (Fig 2 ), even though, when stimulated through the non-dominant eye alone, most cells were 'silent'. The remaining cells did not display significant binocular interactions. For the whole population of neurons, suppression with iso-oriented dichoptic gratings amounted to $29 \cdot 5 \% \pm 4.8 \%$ (mean $\pm S E M)$ of monocular, dominant eye responses; orthogonally orientated gratings suppressed monocular responses by $36.4 \% \pm 3.0 \%$ (mean $\pm S E M$ ). In contrast, in five normal animals, 42 out of 52 neurons $(81 \%)$ showed significant binocular facilitation and only four $(8 \%)$ showed orientation independent interocular suppression. ${ }^{33}$

Interocular suppression in the strabismic animals was characterised by a relative independence of stimulus variables, ${ }^{48}$ in particular a virtual absence of orientation selectivity. Suppression with iso-oriented dichoptic gratings was also independent of the relative disparity of the two gratings (and therefore not related to perceived depth), and it could be elicited by gratings of a wide range of spatial frequencies (often wider than the range of spatial
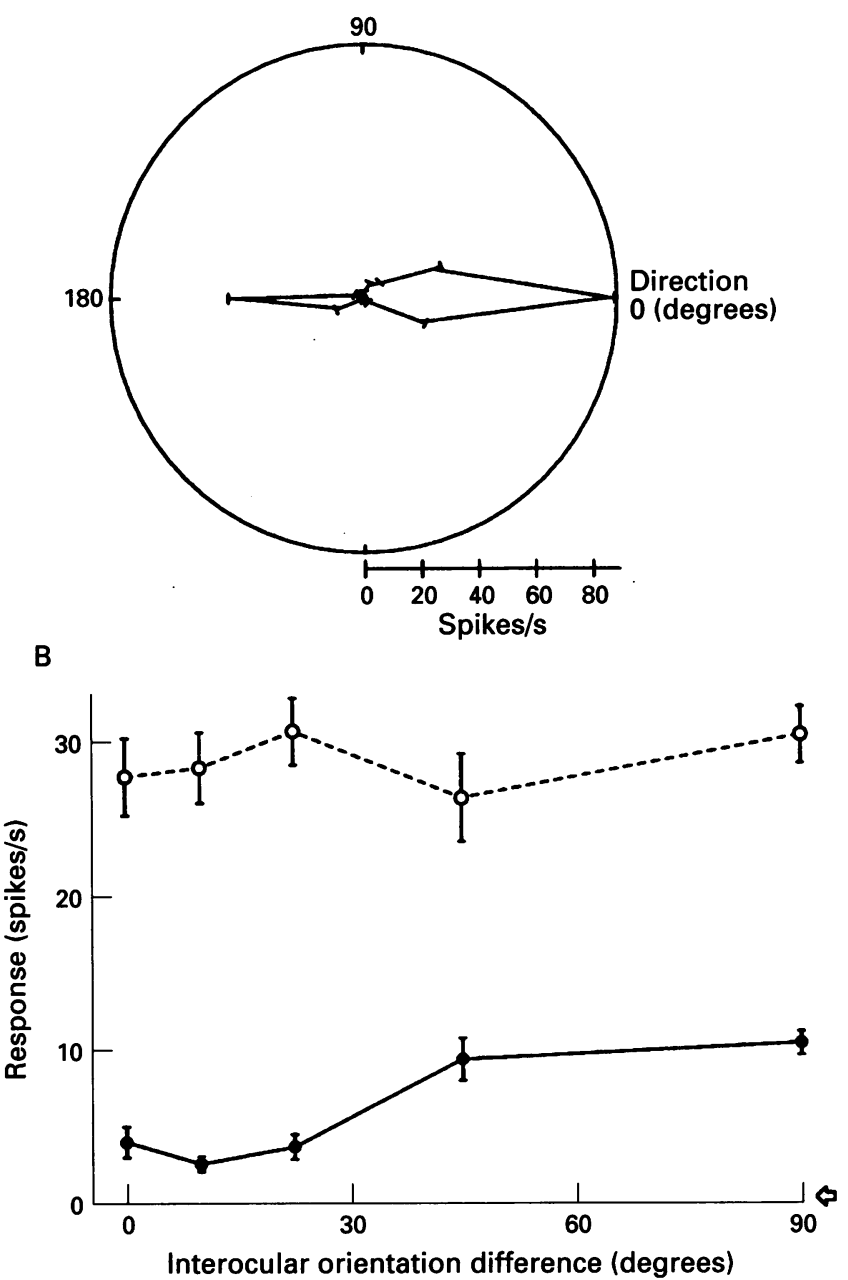

Figure 2 Orientation independence of binocular interaction in a layer 5 complex cell recorded from an exotropic cat (angle of squint, $30^{\circ}$ ).

(A) Polar plot of orientation/direction tuning, as in Figure $1 A$, showing mean responses (+1 SEM) during monocular stimulation with drifting gratings (spatial frequency $=0.56 \mathrm{cpd}$; drift frequency $=4 \mathrm{c} / \mathrm{s}$;

contrast $=0.7)$ through the deviating eye, which was dominant for this cell. There was no significant response through the other (non-deviating) eye. The spontaneous activity of this cell was very low $(<1$ spike/s).

(B) Results of binocular interaction protocol, as in Figure 1B. The deviating (dominant) eye was continuously stimulated with a 'conditioning' grating of optimal direction of drift $\left(0^{\circ}\right.$; spatial frequency $=0.56 \mathrm{cpd}$; temporal frequency $=4 \mathrm{c} / \mathrm{s}$; contrast $=0 \cdot 18$ ), while gratings appeared intermittently in the normal ('silent') eye at five different orientations (same spatial and temporal frequency; contrast $=0 \cdot 7)$, clockwise from that of the 'conditioning' stimulus. The abscissa indicates the difference in orientation between the stimuli shown to the two eyes. ( $\bullet)$ Plots the mean response ( \pm 1 SEM) during binocular stimulation with a particular combination of gratings, while $(O)$ plotted at the same position on the abscissa shows activity averaged over the immediately preceding periods of monocular stimulation. The open arrow indicates the very low level of spontaneous discharge. For this cell, interocular suppression varied between 65 and $90 \%$ of monocular response levels.

frequencies that would trigger an excitatory monocular response). It should be noted, that even for some 'binocular' neurons suppression of responses elicited through one eye was seen when an additional grating was presented to the other eye; a similar finding has been reported by Crewther and Crewther. ${ }^{59}$

Since, in all animals tested, most cells had lost conventional (that is, excitatory) input from one eye or the other, the 'monocular' cells ( $69 \%$ of the total) behaved in a way that would be expected on the basis of the results from normal animals and in the absence of binocular facilitatory interactions for stimuli of matched orientation. The response properties of single cells in V1 of normal and strabismic animals were similar in many respects; for dichoptic gratings of orthogonal orientations (where facilitation is 
absent in normal as well as in strabismic animals), average suppression was of very similar strength (35-40\%) in both normal and strabismic cats (see above). Moreover, neuronal interocular suppression in both normal and strabismic animals was characterised by disparity independence, broad spatial frequency tuning, dependence on the sequence of stimulus presentation, and divisive response gain reduction. ${ }^{38} 48$ Thus normal binocular interaction appears to be the sum of highly stimulus specific facilitation and rather non-selective suppression ${ }^{60}$; strabismus seems to reduce or eliminate the facilitatory interactions, but leaves the non-selective suppression intact.

\section{A neural model of suppression}

We speculate that strabismic suppression in moderate and large angle strabismus is based on inhibitory interactions between neighbouring ocular dominance columns with input from all orientations, combined with the loss of disparity selective interactions for matched stimuli. In small angle strabismus, these inhibitory interactions could account for central suppression, at least for high spatial frequencies where ocular misalignment is sufficiently large to prevent any binocular facilitatory interactions. ${ }^{6}$ Such inhibition deriving from a pool of cells, which represent a wide range of orientations and spatial frequencies, could account for both the virtual absence of selectivity - for example, for orientation that we observed for suppression at the neuronal level, and that which has been described for perceptual suppression in strabismic humans. ${ }^{14}$ The similarity between interocular suppression in V1 of strabismic animals and that produced by orthogonal stimuli presented to the two eyes of normal cats supports the hypothesis that one of the forms of strabismic suppression and binocular rivalry depends on similar neural mechanisms. ${ }^{30-1248}$ It seems possible that, in the long term, such strong interocular suppression will, if unbalanced between the two eyes, result in a central suppression scotoma and strabismic amblyopia. ${ }^{6}$ We have recently obtained evidence that, like in many human strabismic amblyopes, ${ }^{6}$ suppression in V1 of microstrabismic cats is strongest near the representation of the centre of the visual field, while in the periphery close to normal binocular interactions prevail (Sengpiel, Harrad, Freeman, and Blakemore, unpublished observation). Amblyopia might develop if, in a strabismic animal, the neurons in the ocular dominance columns with input from the deviating eye are held constantly inhibited by suppression from the other eye's columns; their inactivity would be likely to interfere with the process of synaptic learning (that is, strengthening of synapses) which, according to Hebb's theory, ${ }^{61}$ is thought to depend on the detection of coincidence of presynaptic and postsynaptic activity (for a review, see Rauschecker ${ }^{62}$ ).

A recent study of the early development of binocular interactions in V1 of kittens with optically induced strabismus indicated that suppressive interocular interactions are strongest shortly after the onset of squint and gradually weaken the longer the deviation persists. ${ }^{63}$ Though at first sight counterintuitive, such a time course may explain the inverse correlation between the strengths of amblyopia and suppression in strabismic humans. ${ }^{14}$ Data from one animal in our study ${ }^{48}$ appear to support the notion that suppression decreases once deep amblyopia is established, as if there were no longer a 'need' for strong suppression of the amblyopic eye to eliminate double vision.

There is a powerful drive in the visual system to abolish diplopia and to achieve the best possible vision, albeit through one eye only. These needs are met by a combination of processes: contrast masking, fusional suppression, disparity dependent suppression, and rivalry-like interocular suppression. The first appears to prevail in anisometropic amblyopia, ${ }^{7}$ the latter three in strabismic amblyopia. That these processes are not identical psychophysically or physiologically with those found in normal subjects can be accounted for by minor modifications in the underlying neural circuitry occurring during visual development.

This work was in part supported by the Medical Research Council and the Oxford McDonnell-Pew Centre for Cognitive Neuroscience. FS holds a fellowship at Magdalen College, Oxford.

RICHARD HARRAD

Bristol Eye Hospital,

Lower Maudlin Street,

Bristol BS1 2LX

University Laboratory of Physiology,

FRANK SENGPIEL

University Laboratory of Physio

\section{COLIN BLAKEMORE}

1 von Graefe A. Das Sehen der Schielenden. Eine ophthalmologisch-physiologische Studie. Wiesbaden, 1896.

2 Travers T. Suppression of vision in squint and its association with retinal correspondence and amblyopia. Br f Ophthalmol 1938; 22: 577-604.

3 Duke-Elder S, Wybar KC. In: Duke-Elder S, ed. System of ophthalmology. London: Henry Kimpton, 1973.

4 Pratt-Johnson JA, Tillson G. Suppression in strabismus - an update. $B r \mathcal{F}$ Ophthalmol 1984; 68: 174-8.

5 Jampolsky A. Characteristics of suppression in strabismus. $A M A$ Arch Ophthalmol 1955; 54: 683-96.

6 Sireteanu R, Fronius M. Naso-temporal asymmetries in human amblyopia: consequence of long-term interocular suppression. Vision Res $1981 ; 21$ 1055-63.

7 Harrad RA, Hess RF. Binocular integration of contrast information in amblyopia. Vision Res 1992; 32: 2135-50.

8 Wheatstone C. Contributions to the physiology of vision. Part the first: on some remarkable, and hitherto unobserved, phenomena of binocular vision. Phil Trans $R$ Soc Lond 1838; 128: 371-94.

9 Blake R. A neural theory of binocular rivalry. Psychol Rev 1989; 96: 145-67.

10 Fahle $M$. Non-fusable stimuli and the role of binocular inhibition in norma and pathologic vision, especially strabismus. Doc Ophthalmol 1983; 55: 323-40.

11 Wolfe JM. Briefly presented stimuli can disrupt constant suppression and binocular rivalry suppression. Perception 1986; 15: 413-7.

12 Von Noorden GK. Binocular vision and ocular motility - theory and management of strabismus. St Louis: C V Mosby, 1990.

13 Smith III EL, Levi DM, Manny RE, Harwerth RS, White JM. The relationship between binocular rivalry and strabismic suppression. Invest Ophthalmol Vis Sci 1985; 26: 80-7.

14 Holopigian K, Blake R, Greenwald MJ. Clinical suppression and amblyopia. Invest Ophthalmol Vis Sci 1988; 29: 444-51.

15 Harrad RA, Hess RF. A model for suppression in amblyopia. In: Kaufmann $\mathrm{H}$, ed. Transactions of the 20th Meeting of the European Strabismological Association 1992: 113-8.

16 Schor CM. Visual stimuli for strabismic suppression. Perception 1977; 6: 583-93.

17 Abadi RV. Induction masking - a study of some inhibitory interactions during dichoptic viewing. Vision Res 1976; 16: 269-75.

18 Legge GE. Spatial frequency masking in human vision: binocular interactions. F Opt Soc Am 1979; 69: 838-74.

19 Levi DM, Harwerth RS, Smith III EL. Humans deprived of normal binocular vision have binocular interactions tuned to size and orientation. Science 1979; 206: 852-4.

20 Holopigian K, Blake R, Greenwald MJ. Selective losses in binocular vision in anisometropic amblyopia. Vision Res 1986; 26: 621-7.

21 Schor CM, Heckmann T. Interocular difference in contrast and spatial frequency: effects on stereopsis and fusion. Vision Res 1989; 29: 837-47.

22 Legge GE, Gu Y. Stereopsis and contrast. Vision Res 1989; 29: 989-1004.

23 Halpern DL, Blake R. How contrast affects stereoacuity. Perception 1988; 17: 483-96.

24 McKee SP, Levi DM, Bowne SF. The imprecision of stereopsis. Vision Res 1990; 30: 1763-79.

25 McKee SP, Harrad RA. Fusional suppression in normal and stereoanomalous observers. Vision Res 1993; 33: 1645-58.

26 Richards W. Stereopsis and stereoblindness. Exp Brain Res 1970; 10: 380-8.

27 Richards W. Anomalous stereoscopic depth perception. $\mathcal{f}$ Opt Soc Am 1971, 61: 410-4.

28 Schor C. Zero retinal image disparity: a stimulus for suppression in small angle strabismus. Doc Ophthalmol 1978; 46: 149-60.

29 Lehky SR, Blake R. Organization of binocular pathways: modeling and data related to rivalry. Neural Comput 1991; 3: 444-53.

30 Hess RF. The site and nature of suppression in squint amblyopia. Vision Res 1991; 31: 111-7.

31 Blakemore C, Campbell FW. On the existence of neurones in the human visual system selectively sensitive to the orientation and size of retinal images. F Physiol 1969; 203: 237-60

32 Varela FJ, Singer W. Neuronal dynamics in the visual corticothalamic path way revealed through binocular rivalry. Exp Brain Res 1987; 66: 10-20.

33 Sengpiel F, Blakemore C, Harrad R. Interocular suppression in the primary visual cortex: a possible neural basis of binocular rivalry. Vision Res 1995, 35: $179-95$.

34 Moore RJ, Spear PD, Kim CBY, Xue JT. Binocular processing in the cat's dorsal lateral geniculate nucleus. III. Spatial frequency, orientation, and direction sensitivity of nondominant-eye influences. Exp Brain Res 1992; 89: 588-98. 
35 Ohzawa I, Freeman RD. The binocular organization of simple cells in the cat's visual cortex. $\Im$ Neurophysiol 1986; 56: 221-42.

36 Ohzawa I, Freeman RD. The binocular organization of complex cells in the cat's visual cortex. $\mathcal{F}$ Neurophysiol 1986; 56: 243-59.

37 DeAngelis GC, Robson JG, Ohzawa I, Freeman RD. Organization of suppression in receptive fields of neurons in cat striate cortex. F Neurophysiol pression in receptive

38 Sengpiel F, Blakemore $C$. Interocular control of neuronal responsiveness in cat visual cortex. Nature 1994; 368: 847-50.

39 Leopold DA, Logothetis NK. Cell activity reflects monkey's perception during binocular rivalry. Invest Ophthalmol Vis Sci 1995; 36: S813.

40 Ikeda H, Wright MJ. Properties of LGN cells in kittens reared with convergent squint: a neurophysiological demonstration of amblyopia. Exp Brain Res 1976; 25: 63-77.

41 Ikeda H, Tremain KE. Amblyopia occurs in retinal ganglion cells in cats reared with convergent squint without alternating fixation. Exp Brain Res 1979; 35: 559-82

42 Cleland BG, Crewther DP, Crewther SG, Mitchell DE. Normality of spatial resolution of retinal ganglion cells in cats with strabismic amblyopia.

43 Hubel DH, Wiesel TN. Binocular interaction in striate cortex of kittens reared with artificial squint. $\mathcal{F}$ Neurophysiol 1965; 28: 1041-59.

44 Blakemore $C$. The conditions required for the maintenance of binocularity in the kitten's visual cortex. F Physiol 1976; 261: 423-44.

45 Van Sluyters RC, Levitt FB. Experimental strabismus in the kitten. $\Im$ Neurophysiol 1980; 43: 686-99.

46 Singer W, von Grünau MW, Rauschecker JP. Functional amblyopia in kittens with unilateral exotropia. I. Electrophysiological assessment. Exp Brain Res 1980; 40: 294-304

47 Crewther DP, Crewther SG. Neural site of strabismic amblyopia in cats: spatial frequency deficit in primary cortical neurons. Exp Brain Res 1990; 79: $615-22$.

48 Sengpiel F, Blakemore C, Kind PC, Harrad R. Interocular suppression in the visual cortex of strabismic cats. $\mathcal{f}$ Neurosci $1994 ; 14: 6855-71$.

49 Baker FH, Grigg P, Von Noorden GK. Effects of visual deprivation and strabismus on the response of neurons in the visual cortex of the monkey, including studies on the striate and prestriate cortex in the normal animal. Brain Res 1974; 66: 185-208.
50 Crawford MLJ, von Noorden GK. The effects of short-term experimental strabismus on the visual system in Macaca mulatta. Invest Ophthalmol Vis Sci 1979; 18: 496-505.

51 Crawford MLJ, Smith III EL, Harwerth RS, von Noorden GK. Stereoblind monkeys have few binocular neurons. Invest Ophthalmol Vis Sci 1984; 25: 779-81.

52 Mitchell DE. In: Shinkman PG, ed. Advances in neural and behavioral development. Norwood, NJ, USA: Ablex Publishing Corp, 1988 209-69.

53 Swindale NV, Mitchell DE. Comparison of receptive field properties of neurones in area 17 of normal and bilaterally amblyopic cats. Exp Brain Res 1994; 99: 399-410.

54 Blakemore C. Maturation of mechanisms for efficient spatial vision. In: Blakemore C, ed. Vision: coding and efficiency. Cambridge: Cambridge University Press, 1990: 254-66.

55 Blakemore C, Eggers HM. In: Cool SJ, Smith III EL, ed. Frontiers in visual science. New York: Springer-Verlag, 1979: 651-9.

56 Blakemore C, Vital-Durand F. Different neural origins for 'blur' amblyopia and strabismic amblyopia. Ophthalmic Physiol Opt 1992; 12: 83.

57 Roelfsema PR, König P, Engel AK, Sireteanu R, Singer W. Reduced synchronization in the visual cortex of cats with strabismic amblyopia. Eur $\mathcal{F}$ Neurosci 1994; 6: 1645-55.

58 Sengpiel F, Kind P, Harrad RA, Blakemore C. Interocular suppression in area 17 of strabismic cats. Invest Ophthalmol Vis Sci 1993; 34 909.

59 Crewther SG, Crewther DP. Amblyopia and suppression in binocular cortical neurones of strabismic cats. NeuroReport 1993; 4: 1083-6.

60 Sengpiel F, Freeman TCB, Blakemore C. Interocular suppression in cat striate cortex is not orientation selective. NeuroReport 1995; 6: 2235-9.

61 Hebb DO. The organization of behavior. New York: Wiley, 1949.

62 Rauschecker JP. Mechanisms of visual plasticity: Hebb synapses, NMDA receptors and beyond. Physiol Rev 1991; 71: 587-615.

63 Chino YM, Smith III EL, Yoshida K, Cheng H, Hamamoto J. Binocular interactions in striate cortical neurons of cats reared with discordant visua inputs. F Neurosci 1994; 14: 5050-67. 